\title{
Nasopharyngeal carriage of neisseria meningitidis among medical school students in Turkey.
}

\author{
Bahar Akgün Karapınar*, Caner Yürüyen, Nezahat Gürler, Çiğdem Kayacan \\ Department of Medical Microbiology, Faculty of Medicine, İstanbul University, 34390 Fatih, İstanbul, Turkey
}

\begin{abstract}
Objective: Neisseria meningitidis can colonise healthy human nasopharynx and is one of the most important etiologic agent of epidemic meningitis. The purpose of this study is to investigate the carriage rate, serogroup distribution and antibiotic resistance of Neisseria meningitidis in medical faculty students.

Methods: Nasopharyngeal swab cultures were evaluated. Identification is made by convensional and semi-otomatised system. Serogroup analysis was performed with slide agglutination method. Minimum inhibitor concentration results were evaluated by gradient test. Risk factors for carriage were investigated.

Results: Neisseria meningitidis was isolated from 3 out of $475(0.6 \%)$ students. Two of them were serogroup A and one was serogroup C. All strains were susceptible to penicillin and ceftriaxone. Living in a dormitory and sharing the room with three other students and smoking were found as risk factors. None of the students reported upper respiratory tract infection or antibiotic usage. Other potential pathogenic microorganisms colonising nasopharynx were also identified and most detected of them is methicillin susceptible Staphylococcus aureus (n: 87).

Conclusion: Neisseria meningitidis is one of the leading pathogen in our country as it's in the world. Since serogroups of isolated strains differ from region to region, it's important that every country should conduct regular surveillance in order to utilize an effective vaccine for prevention and outbreak management against this infection.
\end{abstract}

Keywords: Neisseria meningitidis, Nasopharyngeal carriage, Serogroup distribution.

Accepted on April 16, 2018

\section{Introduction}

Neisseria meningitidis ( $N$. meningitidis) is a Gram-negative diplococcus bacteria and it is still identified as a major cause of infection around the world due to the infections and pandemics it can cause. Nasopharyngeal carriage in healthy individuals has been known since 1890. It causes pandemics in closed and semi-closed communities such as childcare centers, military units, universities, schools and houses. It is classified into 13 serogroups as A, B, C, D, X, Y, Z, E, W-135, H, I, K, L [1,2]. The major agents of the disease are the serogroups $\mathrm{A}, \mathrm{B}, \mathrm{C}, \mathrm{Y}$, $\mathrm{W}-135$ [2]. Rate of colonization at nasopharynx is approximately $10 \%$. Carriage mostly depends on the age, and the incidence is $30 \%$ in adolescents and young individuals [3]. $N$. meningitidis can cause many diseases such as septic arthritis, pneumonia, pericarditis alongside meningitis and septicemia $[2,4]$.

Nasopharyngeal carriage can be alleviated by chemoprophylaxis. While initially sulphonamides were used in treatment of the infection, penicillin and chloramphenicol began to be used in 1950s and 1960s. After 1983, betalactamase producing strains were reported, and afterwards, beta-lactamase negative strains with reduced penicillin sensitivity were reported from many countries such as Spain, United Kingdom and United States. Ceftriaxone is recommended for the treatment of infections caused by penicillin-resistant strains. In addition, in treatment and in order to reduce the rate of carriage, rifampin, ciprofloxacin, and ceftriaxone are recommended [4-7].

The follow-up of serogroup distribution by regions will be helpful in pandemic management and epidemiologic studies which follow the efficiency of the vaccine in the prevention of infections. The aim of our study is to investigate the meningitis agent $N$. meningitidis carriage, serogroup distribution, and antibitotic resistance using the nasopharyngeal swab samples from medical school students and contribute to the epidemiologic studies performed in Turkey.

\section{Materials and Methods}

\section{Study design}

Nasopharyngeal carriage of medical school students were evaluated between October 2013 and March 2015. Specimens 
were taken especially during the months of October-January and March-May. One sample was taken from each student in the study. All medical school students accepted in the study were asymptomatic, healthy individuals. The place of residence (i.e., dormitory), number of cohabitants, number of people who sleep in the same room, presence of any upper respiratory tract infections in the last month, antibiotic use, smoking were questioned as the risk factors of carriage. Also microorganisms other than $N$. meningitidis were identified and recorded.

\section{Sample size}

Five hundred students were targeted to take a sample of nasopharyngeal swabs, but 475 students became volunteers.

\section{Laboratory methods}

Nasopharyngeal swab samples were collected using a dacron tipped swab (FLOQSwabs, Copan, Italy) and were plated on $5 \%$ sheep blood chocolate agar and Thayer Martin (BD, USA) agar, and were incubated for $24-48 \mathrm{~h}$ at $35-37^{\circ} \mathrm{C}$ with $5-10 \%$ $\mathrm{CO}_{2}$. Gram staining was performed on suspected colonies growing on the agar and oxidase and catalase tests were performed on those with an appearance of Gram-negative diplococci, and the strains with a positive result from these tests were diagnosed as $N$. meningitidis using API $\mathrm{NH}$ (bioMérieux, France) half-automated system. Serogroups of the strains were identified by slide agglutination method using polyvalent antisera (DifcoTM $N$. meningitidis antiserum group A, B, C, Y, W/135, Becton Dickinson, USA). Gradient test (E test, bioMeriéux, France) was used to identify the sensitivity of these strains to penicillin and ceftriaxone, and results of the minimum inhibitor concentration (MIC) were evaluated based on the recommendations of Clinical Laboratory Standards
Institute (CLSI) [8]. Microorganisms other than $N$. meningitidis were identified using conventional methods (Gram staining, sensitivity to catalase, oxidase, DNAse, cefoxitin, optochin, bile solubility, esculin hydrolysis, glucoselactose-sucrose fermentation, mobility, urease, citrate use, etc.).

\section{Ethical consideration}

The study was approved by National Clinical Research Ethics Committee of İstanbul University Istanbul Medical Faculty (Approval number is 24-2013/12, dated 07.01.2013). The procedures followed were in accordance with the ethical standards of the responsible committee on human experimentation (institutional or regional) and with the Helsinki Declaration of 1975 , as revised in 2000. Written informed consent was obtained from all participants. This work was supported by Scientific Research Projects Coordination Unit of Istanbul University. Project number 30147.

\section{Results}

Nasopharyngeal swab samples of a total of 475 students (181 females and 294 males) aged between 18 and 20 were evaluated. Growth of normal flora bacteria was detected in 309 $(65 \%)$ of these students, and $3(0.6 \%) N$. meningitidis growth was detected. Of these strains, two $(0.4 \%)$ were in serogroup A and $1(0.2 \%)$ was is serogroup C. All these strains were found to be sensitive to penicillin and ceftriaxone (Table 1). One of the carriers was a female, and the others were male student. In terms of the risk factors, one lived in the dormitory and shared a room with three other individuals, and the other one was a smoker. They have not reported antibiotic use and upper respiratory tract infections in the last month. Growth statuses of any colonizing microorganisms other than $N$. meningitidis of 163 students are presented in the Table 2.

Table 1. Distribution of serogroups and antibiotic sensitivity of Neisseria meningitides.

\begin{tabular}{|c|c|c|c|c|c|c|c|c|c|}
\hline \multirow{4}{*}{ Student } & \multirow{4}{*}{ Serogroup distribution } & \multicolumn{8}{|c|}{ Antibiotic sensitivity $\left(\mathrm{MIC}^{1}\right)$} \\
\hline & & \multicolumn{4}{|c|}{ Penicillin } & \multicolumn{4}{|c|}{ Ceftriaxone } \\
\hline & & \multicolumn{3}{|c|}{ MIC Interpretive Criteria ${ }^{2}$} & \multirow{2}{*}{$\begin{array}{l}\text { Isolate } \\
\text { S }\end{array}$} & \multicolumn{3}{|c|}{ MIC Interpretive Criteria ${ }^{2}$} & \multirow{2}{*}{ Isolate } \\
\hline & & $S^{3}$ & $1^{4}$ & $\mathrm{R}^{5}$ & & I & $\mathrm{R}$ & & \\
\hline 1 & Serogroup A & $\leq 0.06$ & - & $\geq 0.12$ & $0.094(\mathrm{~S})$ & $\leq 0.5$ & 1 & $\geq 2$ & $<0.016(S)$ \\
\hline 2 & Serogroup A & $\leq 0.06$ & - & $\geq 0.12$ & $0.008(\mathrm{~S})$ & $\leq 0.5$ & 1 & $\geq 2$ & $0.016(\mathrm{~S})$ \\
\hline 3 & Serogroup C & $\leq 0.06$ & - & $\geq 0.12$ & $0.012(\mathrm{~S})$ & $\leq 0.5$ & 1 & $\geq 2$ & $0.016(\mathrm{~S})$ \\
\hline
\end{tabular}

${ }^{1}$ Minimal inhibitor concentration, ${ }^{2} \mathrm{MIC}$ interpretive criteria for meningitidis, ${ }^{3} \mathrm{~S}$ : Sensitive, ${ }^{4} \mathrm{I}$ : Intermediate, ${ }^{5} \mathrm{R}:$ Resistant

\section{Discussion}

Infections caused by $N$. meningitidis have an important place among the invasive bacterial infections worldwide. While the infections can occur in singular cases, there can be pandemics or even epidemics. This depends on the geographical region and time [9]. Meningococci can be transmitted from asymptomatic carriers or from individuals with upper respiratory tract infection through droplets. Transmission increases in close contact conditions or in crowded places [10]. Similar to age group of our study, carriage rate among children aged 15-19 living in social rehabilitation centers in Mexico is $1.9 \%$, whereas it is $2.9 \%$ in children under 5 years old living in care centers; and no meningococcus was detected in college 
students [11]. In Netherlands, 3,200 healthy children aged 1-19 were $1.15 \%$ carriers [12].

Table 2. Distribution of the microorganisms detected in Nasopharyngeal swab samples other than Neisseria meningitides.

\begin{tabular}{|c|c|}
\hline Microorganism & Number (n) \\
\hline $\mathrm{MSSA}^{1}$ & 87 \\
\hline Moraxella catarrhalis & 18 \\
\hline Streptococcus pneumoniae & 15 \\
\hline Haemophilus influenzae & 15 \\
\hline Haemophilus parainfluenzae & 14 \\
\hline $\mathrm{MRSA}^{2}$ & 6 \\
\hline Enterobacter spp. & 6 \\
\hline Non-GAS ${ }^{3}$ & 5 \\
\hline Klebsiella pneumoniae & 4 \\
\hline Klebsiella oxytoca & 2 \\
\hline Klebsiella ozaneae & 1 \\
\hline Serratia spp. & 1 \\
\hline Citrobacter spp. & 1 \\
\hline Pseudomonas aeruginosa & 1 \\
\hline NFGNR ${ }^{4}$ & 1 \\
\hline Enterococcus spp. & 1 \\
\hline
\end{tabular}

Long term carriage was investigated in 2,453 college students in United Kingdom at different times and carriage rate was changed from $44.1 \%$ to $57.1 \%$. Of those who were initially carriers but stopped being carriers $16 \%$ were recolonized by these bacteria within 6 months. Students, who were not carriers initially, were re-evaluated again $13.7 \%-22.1 \%$ were carriers in another time periods [13]. Worldwide epidemiologic and surveillance studies are performed regularly, and studies on this subject have been performed in the recent years in Turkey $N$. meningitidis carriage prevalence among 1.155 students aged $7-19$ was $10.4 \%$ and the most frequently detected serogroup was serogroup B (47.5\%). In the same study, living in crowded homes and in slums, using stove for heating purposes were identified as risk factors for carriage; tonsillectomy, tonsil hypertrophy, smoking, and being exposed to cigarette smoke were not identified as risk factors [14]. In a study conducted among 1.995 newcomer soldiers, carriage rate was $4.2 \%$ and the most frequently observed serogroups were $\mathrm{Y}$ and $\mathrm{W}-135$, and tetra vaccination was performed instead of bivalan vaccination [15]. In another study, $N$. meningitidis carriage was identified in $0.6 \%$ and all the strains were serogroup B [16].

The incidence of invasive meningococcus is 10-1.000/100.000 in Africa, whereas it is $0.92 / 100.000$ in Europe and $0.28 / 100.000$ in USA [17]. Serogroup distribution is important for vaccine studies and epidemiologic data. Distribution changes according to time and geographical region. Serogroups $\mathrm{B}, \mathrm{C}$, and $\mathrm{Y}$ are frequently observed in USA and Canada, serogroups $\mathrm{B}$ and $\mathrm{C}$ are frequently observed in Europe, whereas in Asia, serogroup A is observed in high rates, and the rates of serogroups $\mathrm{C}, \mathrm{Y}$ and $\mathrm{W}-135$ are increasing. In the region termed "meningitis belt" in Africa, serogroup A frequently causes pandemics $[9,17,18]$. After the pilgrimage season in 2000, there were 90 cases in 9 countries and this raised the importance of $\mathrm{W}-135$ once more [19]. Considering the multicenter study, between 2006-2009, N. meningitidis detected in $19 \%$ of the meningitis patients (86\% serogroup B, $6 \%$ serogroup C, 3\% serogroup A-X-W135) and between $2005-2012$, N. meningitidis was detected in $52.4 \%$ of the meningitis cases (38\% serogroup W135, 26.1\% serogroup B, and $8.4 \%$ serogroup A) [20,21]. In our study, consistent with the data of the other studies performed in Turkey, serogroups A and $\mathrm{C}$ were detected, but serogroups $\mathrm{W}-135$ and $\mathrm{B}$, which were observed more frequently as invasive infection agents, were not detected. Penicillin and ceftriaxone take the lead in $N$. meningitidis treatment. However, beta lactamase can be rarely detected and therefore sensitivity tests must be performed and MIC value should be determined [4]. In a surveillance study performed in USA between 2004-2011, it was found that penicillin sensitivity decreased from $90.8 \%$ to $88.5 \%$, and strains with intermediate level sensitivity increased from $8.5 \%$ to $11.5 \%$, and the resistance decreased from $0.7 \%$ to $0 \%$. Ceftriaxone sensitivity was $100 \%$ [22]. National surveillance data in-between 1960-2012 were analyzed in Netherlands and penicillin resistance was not detected in 15.412 cases [23]. While the number of strains detected in our study is less, all strains were sensitive to penicillin and ceftriaxone.

While investigating nasopharyngeal $N$. meningitidis carriage in our study, other potential pathogenic microorganisms colonized in nasopharynx were detected in the meantime. In nasopharyngeal carriage studies, Farida et al. found $15 \% \mathrm{~K}$. pneumoniae, 4\% Pseudomonas spp., 4\% Enterobacter spp., $1 \%$ A. baumannii in adults; and Hassaun et al. investigated 100 asymptomatic medical staff and 51.4\%-55.9\% MRSA, 17.6\%-29.7\% MSSA, 24.9\% M. catarrhalis and $21.6 \% \mathrm{~K}$. pneumoniae were investigated [24,25]. S. pneumoniae and $H$. influenzae were detected in lower rates. MSSA, MRSA, $M$. catarrhalis and $K$. pneumoniae were the most frequently observed microorganisms in school of medicine students [25]. In our study the most frequently encountered microorganism was MSSA (18.3\%), contrary to the MRSA which was frequently observed in other studies. Consistent with the previous studies, Gram-negative rods except $M$. catarrhalis (3.7\%), S. pneumoniae (3.1\%), H. influenzae (3.1\%) and Enterobacter spp. and Klebsiella spp. were observed less frequently in our study. Neisseria meningitidis is among the primary pathogens in Turkey as it is in the world. We believe that our study results would contribute to the epidemiologic data of our country. 


\section{References}

1. Apicella MA. Neisseria meningitidis. In: Mandell, Douglas, and Bennett's Principles and Practice of Infectious Diseases. 7th ed Churchill Livingstone, Philadelphia 2010.

2. Hill DJ, Griffiths NJ, Borodina E, Virji M. Cellular and molecular biology of Neisseria meningitidis colonization and invasive disease. Clin Sci 2010; 118: 547-564.

3. Elias J, Frosch M, Vogel U. Neisseria. In: Manual of Clinical Microbiology. 10th ed ASM press, Washington 2011.

4. Gürler N. Microbiology and resistance in pneumococcal and meningococcal infections in Turkey and in the world. J Pediatr Inf 2011; 5: 15-25.

5. Yazdankhah SP, Caugant DA. Neisseria meningitidis: an overview of the carriage state. J Med Microbiol 2004; 53: 821-832.

6. Manchanda V, Gupta S, Bhalla P. Meningococcal disease: history, epidemiology, pathogenesis, clinical manifestations, diagnosis, antimicrobial susceptibility and prevention. Indian J Med Microbiol 2006; 24: 7-19.

7. Centers for Disease Control and Prevention. Prevention and Control of Meningococcal Disease Recommendations of the Advisory Committee on Immunization Practices (ACIP). MMWR 2005; 54: 1-17.

8. Clinical and Laboratory Standards Institute. Performance standards for antimicrobial susceptibility testing. Twentyfourth Information Supplement, 2014. M100-S24. CLSI, Wayne, PA.

9. Harrison LH, Trotter CL, Ramsay ME. Global epidemiology of meningococcal disease. Vaccine 2009; 27: 51-63.

10. Chang Q, Tzeng Y, Stephens DS. Meningococcal disease: changes in epidemiology and prevention. Clin Epidemiol 2012; 4: 237-245.

11. Espinosa de los Monteros LE, Aguilar-Ituarte F, JiménezRojas LV, Kuri P, Rodríguez-Suárez RS, Gómez-Barreto D. Prevalence of Neisseria meningitidis carriers in children under five years of age and teenagers in certain populations of Mexico city. Salud Publica Mex 2009; 51: 114-118.

12. Bogaert D, Hermans PWM, Boelens H, Slujiter M, Luijendijk A, Rumke HC, Koppen S, van Belkum A, de Groot R, Verbrugh HA. Epidemiology of nasopharyngeal carriage of Neisseria meningitidis in healthy dutch children. Clin Infect Dis. 2005; 40: 899-902.

13. Ala'aldeen DAA, Neal KR, Ait-Tahar K, Nyugen-VanTam JS, English A, Falla TJ, Hawkey PM, Slack RC. Dynamics of meningococcal long-term carriage among university students and their implications for mass vaccination. J Clin Microbiol 2000; 38: 2311-2316.

14. Ercis S, Köseoğlu Ö, Salmanzadeh-Ahrabi S, Ercis M, Akın L, Hasçelik G. The prevalence of nasopharyngeal Neisseria meningitidis carriage, serogroup distribution, and antibiotic resistance among healthy children in
Çankaya municipality schools of Ankara province. Mikrobiyol Bul 2005; 39: 411-420.

15. Başustaoğlu AC, Bedir O, Yılmaz S, Kılıç A, Gümral R, Mert G, Beşirbellioğlu B. Nasopharyngeal carriage rate and serogroups of Neisseria meningitidis in Turkish recruits upon entry to the military. TAF Prev Med Bull 2011; 10: 447-450.

16. Kadayifci EK, Merdan DG, Soysal A, Karaaslan A, Atıcı S, Durmaz R, Boran P, Turan I, Söyletir G, Bakır M. Prevalence of Neisseria meningitidis carriage: a smallscale survey in Istanbul, Turkey. J Infect Dev Ctries 2016; 10: 413-417.

17. Halperin SA, Bettinger JA, Greenwood B, Harrison LH, Jelfs J, Ladhani SN, Mcintyre P, Ramsay ME, Sáfadi MA. The changing and dynamic epidemiology of meningococcal disease. Vaccine 2012; 30: 26-36.

18. Vyse A, Wolter JM, Chen J, NG T, Soriano-gabarro M. Meningococcal disease in Asia: an under-recognized public health burden. Epidemiol Infect 2011; 139: 967-985.

19. Aguilera J, Perrocheau A, Meffre C, Hahné S, W135 Working Group. Outbreak of serogroup W135 meningococcal disease after the hajj pilgrimage, Europe, 2000. Emerg Infect Dis 2002; 8: 761-767.

20. Toprak D, Soysal A, Torunoğlu MA, Turgut M, Türkoğlu S, Pimenta FC, Carvalho Mda G, Wang X, Mayer L, Altnkanat G, Söyletir G, Mete B, Bakr M. PCR-based national bacterial meningitis surveillance in Turkey years 2006 to 2009. Pediatr Infect Dis J 2014; 33: 1087-1089.

21. Ceyhan M, Gürler N, Ozsurekci Y, Keser M, Aycan AE, Gurbuz V, Salman N, Camcioglu Y, Dinleyici EC, Ozkan S, Sensoy G, Belet N, Alhan E, Hacimustafaoglu M, Celebi S, Uzun H, Oner AF, Kurugol Z, Tas MA, Aygun D, Karadag Oncel E, Celik M, Yasa O, Akin F, Coşkun Y. Meningitis caused by Neisseria meningitidis, Hemophilus influenzae Type B and Streptococcus pneumoniae during 2005-2012 in Turkey, Hum Vaccin Immunother. 2014; 10 : 2706-2712.

22. Harcourt BH, Anderson RD, Wu HM, Cohn AC, MacNeil JR, Taylor TH, Wang X, Clark TA, Messonnier NE, Mayer LW. Population-based surveillance of Neisseria meningitidis antimicrobial resistance in the United States. Open Forum Infect Dis 2015; 2: 117.

23. Bijlsma MW, Bekker V, Brouwer MC, Spanjaard L, van de Beek D, van der Ende A. Epidemiology of invasive meningococcal disease in the Netherlands, 1960-2012: an analysis of national surveillance data. Lancet Infect Dis 2014; 14: 805-812.

24. Farida H, Severin JA, Gasem MH, Keuter M, van den Broek P, Hermans PWM, Wahyono H, Verbrugh HA. Nasopharyngeal carriage of Klebsiella pneumoniae and other gram-negative bacilli in pneumonia-prone age groups in Semarang, Indonesia. J Clin Microbiol 2013; 51: 1614-1616.

25. Hassoun A, Huff MD, Weisman D, Khushdeep C, Asis E, Stalons D, Grigorenko E, Green J, Malone LL, Clemmons 
Nasopharyngeal carriage of neisseria meningitidis among medical school students in Turkey

$\mathrm{S}$, Lu S. Seasonal variation of respiratory pathogen colonization in asymptomatic health care professionals: a single-center, cross-sectional, 2-season observational study. Am J Infect Control 2015; 43: 865-870.

\section{*Correspondence to}

Bahar Akgün Karapınar
Department Of Medical Microbiology

Faculty of Medicine

İstanbul University

Turkey 